\title{
A Study on the Strengthening Performance of Concrete Beam by Fiber-Reinforced Polyurea (FRPU) Reinforcement
}

\author{
Jun-Hyuk Song, ${ }^{1}$ Eun-Taik Lee, ${ }^{2}$ and Hee-Chang Eun $\mathbb{D}^{1}$ \\ ${ }^{1}$ Department of Architectural Engineering, Kangwon National University, Chuncheon, Republic of Korea \\ ${ }^{2}$ Department of Architectural Engineering, Chung-Ang University, Seoul, Republic of Korea \\ Correspondence should be addressed to Hee-Chang Eun; heechang@kangwon.ac.kr
}

Received 14 May 2019; Accepted 29 July 2019; Published 11 March 2020

Guest Editor: Charis Apostolopoulos

Copyright (C) 2020 Jun-Hyuk Song et al. This is an open access article distributed under the Creative Commons Attribution License, which permits unrestricted use, distribution, and reproduction in any medium, provided the original work is properly cited.

\begin{abstract}
Polyurea coating helps improve the ductility and toughness of structural members. A fiber-reinforced polyurea (FRPU) composite provides high load-carrying capacity and is applied by simply spraying it onto the member surface. Unlike existing reinforcement approaches, the FRPU coating method can prevent the ductility of concrete beams from deteriorating and the concrete surface from debonding. In this study, 20 concrete beams were tested with respect to their load-carrying capacity and flexural ductility using polyurea or FRPU reinforcement. The test variables included the type of reinforcing fibers, coating thickness, and weight-tocontent ratio of the fibers in the FRPU. Moreover, the load-carrying capacity and mechanical behavior of all specimens were compared according to the content of the steel fibers, milled glass fibers, or carbon nanotubes (CNTs). Specimens reinforced using polyurea or FRPU were confirmed to retain the load-carrying capacity and flexural ductility to a certain degree after concrete failure at the tension face of the midspan section. The concrete beams ultimately failed through the fracture of polyurea or FRPU without debonding. Experiments were conducted to illustrate the strengthening effect by FRPU and determine its superiority.
\end{abstract}

\section{Introduction}

Elastomers are a class of polymetric materials. An elastomer has viscoelasticity, with a low elastic modulus and high yield strain. Polyurea is an elastomeric polymer derived from the rapid reaction of an isocyanate component and polyamine and is considered a versatile material. It has been utilized as a flooring and waterproofing material to prevent shrinkage when drying. It has a high tensile strength, elongation, and the capability to absorb the energy generated through dynamic and impulsive blast loading. In addition, it represents a good adhesion to concrete and can increase the toughness and flexural strength of the concrete, decreasing the stiffness. Polyurea coatings combine high flexibility with hardness and high elasticity with a high surface hardness.

Owing to the increased loading requirements, change in use, and structural deterioration, the structural performance can be recovered using retrofitting techniques. Building structures need to be evaluated and effectively implemented, with economical repair and strengthening capabilities. Polyurea achieves flexural and shear reinforcement for structural members rather than blast or impact mitigation [1] and can improve the seismic performance of structures, controlling the plastic hinge occurrence, increasing the deformation capacity and dissipated energy, strengthening or changing the structural system, and enhancing the lateral stiffness. Marawan et al. [2] observed an increase in the flexural and shear capacity of small- and large-scale beams strengthened using a sprayed polyurea system depending on the thickness of the polyurea applied. Parniani and Toutanji [1] investigated the behavior of concrete beams strengthened using a polyurea coating system. They found that the polyurea coating system increases the flexural capacity and ductility of reinforced concrete beams. Kamonchaivanich et al. [3] compared the flexural strength of a back-coated ceramic with polyurea of a lower and higher modulus.

Structural-strengthening techniques include a section enlargement, a reinforced jacketing of externally bonded 
steel elements, fiber reinforced polymer (FRP) composites, and other factors. There have been numerous studies related with an enhancement of the load-carrying capacity and ductility of a concrete member using FRP, which has been utilized in repairing and strengthening aged and performance-deteriorated structures, including their end of service life, steel corrosion, and concrete spalling. FRPs of a high tensile strength and low weight fail through concrete cover separation and interfacial debonding. Numerous analytical models have been developed to describe the mechanical characteristics of concrete externally confined with FRP composites [4-10].

The FRP composites are made up of fibers with a high tensile strength embedded in an epoxy matrix. An explicit bonding to achieve sufficient adhesiveness between the FRP composites and concrete structures is required for transferring the stress among them. Gideon and Alagusundaramoorthy [11] studied the flexural behavior and failure mode of concrete beam prototypes with a high shear span ratio externally bonded using carbon fiber-reinforced polymer (CFRP) laminates. Li et al. [12] determined that the variation in shear capacity of a strengthened beam depends strongly on the strengthened area. Alferjani et al. [13] observed that an epoxy resin is favorable in strengthening and an end anchorage is needed to eliminate debonding failures. FRP-strengthened beams exhibit debonding failure modes at the end of the beams without an end anchorage and a rupture of the FRP in beams with an end anchorage [14-21]. Uomoto et al. [22] introduced FRP composites to combine the structural and durability characteristics of FRPs as reinforcement in concrete constructions. Mahiyar and Soni [23] observed that the utilization of an FRP grid is extremely effective in enhancing the flexural strength of concrete.

FRPU is a composite used to mix elastic polyurea with fibers for a more enhanced load-carrying capacity and greater mechanical properties. FRPU coating systems can yield a multihazard retrofit material suitable for aging structures. Such systems must be useful in repair and retrofit applications for strengthening the structural capacity, improving the seismic performance, and mitigating blast and impact damage.

A polyurea or FRPU spraying method can prevent the debonding of FRP or steel plates from concrete surfaces and retain sufficient ductility. The fiber addition provides improved stiffness and strength to a composite system, whereas polyurea provides ductility. Greene and Myers [24] investigated the flexural and shear reinforcement capabilities of the systems provided by externally applied discrete fiberreinforced polyurea (DFRP) coating systems. A DFRP system is a composite system used to simultaneously spray polyurea and chopped glass fibers into a spray pattern. A measurable strengthening in terms of both flexural and shear capacity, along with substantial gains in ductility, was found. In addition, they mentioned that an increased fiber length significantly reduces the ductility. Carey and Myers [25] also considered the addition of discrete chopped fibers to the polyurea for additional strength and a more developed fiber characterization of the polyurea system.
The present study investigates the applicability of FRPU when containing fiber reinforcements such as milled glass fibers, steel fibers, and carbon nanotubes (CNTs). This can be expected to enhance the load-carrying capacity and improve the ductility. Concrete beam tests were conducted to compare the load-carrying capacity and mechanical behavior depending on the reinforcing materials, spray thickness, and fiber weight-to-content ratio. It was observed that the specimens reinforced using polyurea or FRPU retain the additional load-carrying capacity and flexural ductility after a concrete failure at the tension face of the midspan section. The concrete beams ultimately failed through a fracture of polyurea or FRPU without debonding. The experiment results illustrate the reinforcement effect from the FRPU and the superiority of its application.

\section{Experiment}

2.1. Polyurea and FRPU. FRPU is manufactured by mixing the polyurea of a prepolymer and hardener with fibers. The FRPU moves through the hose after a premixing of the prepolymer and fiber and is simply sprayed onto the surface of the structural member using a high-pressure spray gun with a hardener. The constituents of the polyurea used in this experiment are shown in Table 1.

Three types of fibers, namely, steel fibers, CNTs, and milled glass fibers, were considered during this experiment. Steel fibers are filaments of wire, deformed and cut to various lengths, for the reinforcement of concrete, mortar, and other composite materials. CNTs are utilized as a powder requiring high strength, durability, and lightweight properties as compared to conventional materials. Milled glass fibers are made by cutting E-glass fibers into short pieces. E-glass fibers have an excellent electrical insulation property, can be processed into various shapes, and are mainly applied in the reinforcement of plastics. This is effective in improving not only the strength but also the surface conditions and dimensional stability. This experiment utilizes milled glass fibers of $300 \mu \mathrm{m}$ in length.

As the first step of FRPU spraying, a primer is painted onto the surface of the concrete member, as shown in Figure 1(a), after the laitance, foreign substances, and pollutants are removed to improve the bond performance. After curing for $24 \mathrm{~h}$, the prepolymer and fibers are mixed and stirred, as shown in Figure 1(b), and the premixed prepolymer and fibers are sprayed along with a hardener onto the member surface through the hose of a high-pressure spray gun, as shown in Figure 1(c). After the FRPU coating, the coating is finished with a primer painting, as shown in Figure 1(d). The FRPU coating technology is completed simply and strongly bonded to the member.

2.2. Specimens. Twenty concrete beams without reinforcing bars are prepared for testing. The specimens are designed using a polyurea-reinforced control beam and FRPU-reinforced beams. The parameters of the experiment include the type and weight-to-content ratio of the fiber and the spraying thickness. The thickness effect of single $(3 \mathrm{~mm})$ and 
TABLE 1: Constituents of polyurea.

\begin{tabular}{|c|c|c|}
\hline & Chemicals & Content (\%) \\
\hline \multirow{6}{*}{ Prepolymer } & $\alpha$-(2-Aminomethylethyl)- $\omega$-(2-aminomethylethoxy)poly[oxy(methyl-1,2-ethanediyl)] & $60 \sim 70$ \\
\hline & Ar,ar-diethyl-ar-methylbenzenediamine & $20 \sim 30$ \\
\hline & Poly[oxy(methyl-1,2-ethanediyl)], $\alpha, \alpha^{\prime}, \alpha^{\prime \prime}$-1,2,3-propanetriyltris[ $\omega$-(2-aminomethyl-ethoxy)- & $1 \sim 10$ \\
\hline & Titanium dioxide & $1 \sim 2.7$ \\
\hline & 1,4-Benzenedicarboxylic acid, bis(2-ethylhexyl) ester & $1 \sim 10$ \\
\hline & etc. & $1 \sim 10$ \\
\hline \multirow{2}{*}{ Hardener } & Polyurethane resin & $90 \sim 100$ \\
\hline & 4-Methyl-1,3-dioxolan-2-one & $1 \sim 10$ \\
\hline
\end{tabular}

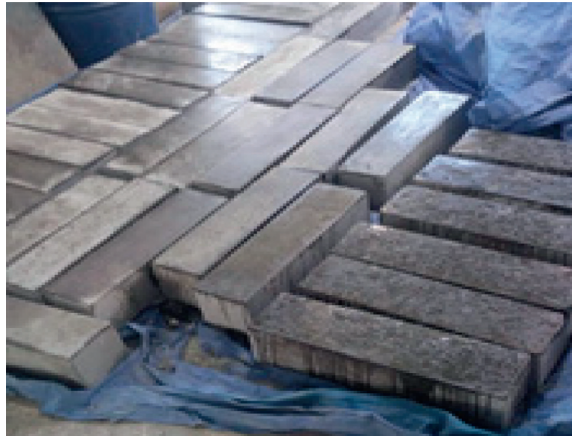

(a)

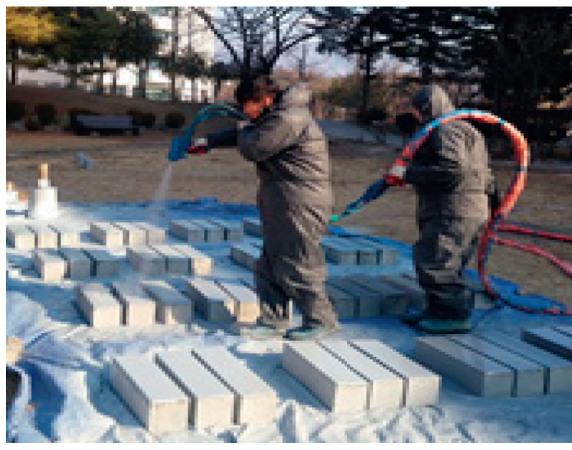

(c)

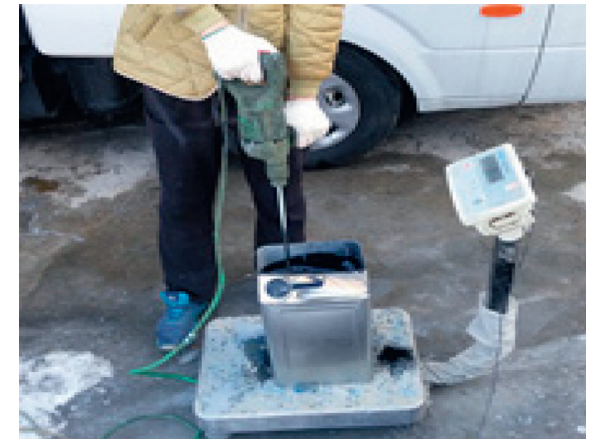

(b)

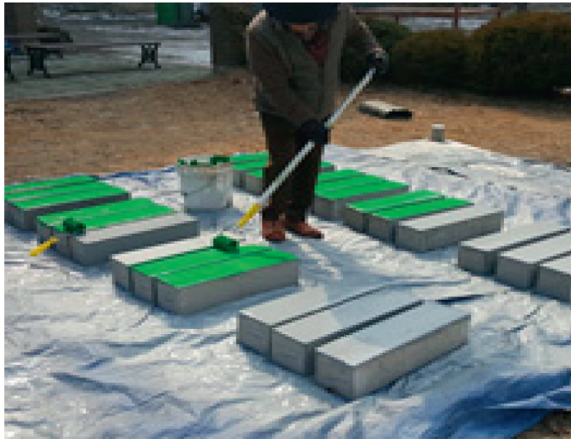

(d)

FIGURE 1: FRPU spraying operation: (a) primer painting; (b) mixing of prepolymer and fibers; (c) FRPU spraying; (d) primer painting.

double $(5 \mathrm{~mm})$ spraying is considered, and the weight-tocontent ratio of the fiber is established as $5 \%, 7 \%$, and $10 \%$ for steel and glass fibers, and $2 \%, 4 \%$, and $6 \%$ for CNTs. The low ratio of the CNTs occurs because of the high cost and high volume from a due to low specific gravity. The steel fibers of $5 \mathrm{~mm}$ in length are scattered before the polyurea is sprayed owing to their difficulty in passing through the hose. The specimens are classified using the sign shown in Figure 2. In the figure, the characters $\mathrm{S}, \mathrm{F}$, and $\mathrm{C}$ denote the steel fibers, milled glass fibers, and CNTs, respectively. In addition, the next number is the weight-to-content ratio of the fibers, and the next numbers 1 and 2 denote the spraying thicknesses of 3 and $5 \mathrm{~mm}$, respectively. The physical properties of FRPU reinforced using 2\% CNTs are shown in Table 2. As the table indicates, the FRPU has a tensile strength of $12 \mathrm{~N} / \mathrm{mm}^{2}$ and an extension rate upon rupture of $240 \%$. In addition, an improved flexural strength and ductility are expected.

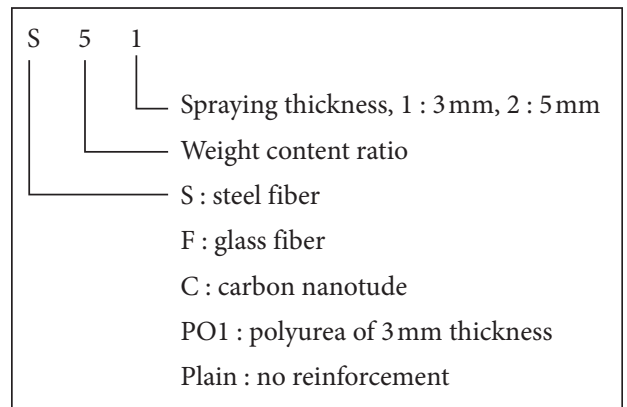

FIgURE 2: Specimen sign.

The five-week compressive strength of concrete after concrete casting is $28 \mathrm{MPa}$. The test beams are strengthened using polyurea or FRPU spraying three days in advance. The polyurea and FRPU act as a lateral reinforcement, leading to an enhanced strength and ductility. However, a polyurea- 
TABLE 2: Physical properties of FRPU containing 2\% CNT.

\begin{tabular}{lcc}
\hline Item & Specification & Result \\
\hline $\begin{array}{l}\text { Amount of water absorption }(\mathrm{g}) \\
\text { Water permeability resistance }\end{array}$ & KS F 4919 & 0.4 \\
Moisture permeability (m) & & No penetration at $0.3 \mathrm{~N} / \mathrm{mm}^{2}$ water pressure \\
\hline Permeation resistance of chloride ion (Coulombs) & KS F 4936 & 3.0 \\
\hline Tensile strength $\left(\mathrm{N} / \mathrm{mm}^{2}\right)$ & & 28 \\
$\begin{array}{l}\text { Extension percentage at rupture (\%) } \\
\text { Bond strength }\left(\mathrm{N} / \mathrm{mm}^{2}\right)\end{array}$ & KS F 4922 & 240 \\
\hline
\end{tabular}

KS: Korean Standards.

reinforced concrete cylinder may be subjected to an eccentric load, and its accurate compressive strength can rarely be measured because the polyurea cannot be sprayed with a constant thickness along the circumferential surface. Figure 3 shows the failure mode of a polyurea-reinforced concrete cylinder through eccentric loading with an irregular expansion of the concrete cylinder. In addition, it is shown that the polyurea constrains the inner core concrete and fails by a loosening of the polyurea used to enclose the concrete pieces. This indicates that polyurea is effective in enhancing the ductility without a debonding.

Concrete beams of size $150 \mathrm{~mm} \times 150 \mathrm{~mm} \times 150 \mathrm{~mm}$ for testing the flexural strength are manufactured without reinforcing bars, and the load is applied at two points on the beam, as shown in Figure 4. The experiment results indicate the flexural performance including the load-carrying capacity and flexural ductility. The initial crack begins at the bottom face of the midspan section. The unreinforced concrete beam simultaneously fails with the advent of the initial cracking because of the low tensile strength of the concrete. The polyurea- and FRPU-reinforced concrete beams exhibit an abrupt reduction in the flexural strength the moment the initial cracking occurs. However, the load after the initial cracking gradually increases and is carried by the polyurea or FRPU on the tension side. The specimens reach the second peak load. The additional cracks are gradually propagated and widen around the midspan with an increase in the load. The polyurea or FRPU controls the development of cracks without peeling from the concrete surface.

Table 3 shows the peak load-carrying capacity, the second peak load, and the flexural ductility. The flexural ductility of the test beams is estimated based on the area under the load-deflection curve prior to failure. In addition, its ratio is calculated by dividing the ductility of FRPUcoated beams through the ductility of the polyurea-coated control beam. The peak load-carrying capacity ratio is determined as the peak load-carrying capacity of the polyureaand FRPU-reinforced concrete beams with respect to that of the control beam. The peak load-carrying capacity of the FRPU-reinforced specimens was shown to be 1.0-1.53, which is as high as that of the polyurea-reinforced specimens, except for C62. The low-density CNTs have a high volume in FRPU. This can therefore lead to a discontinuous load-transferring path owing to the unevenness of the CNTs and the deteriorated flexural strength. In addition, all specimens except S51 represent a more improved flexural

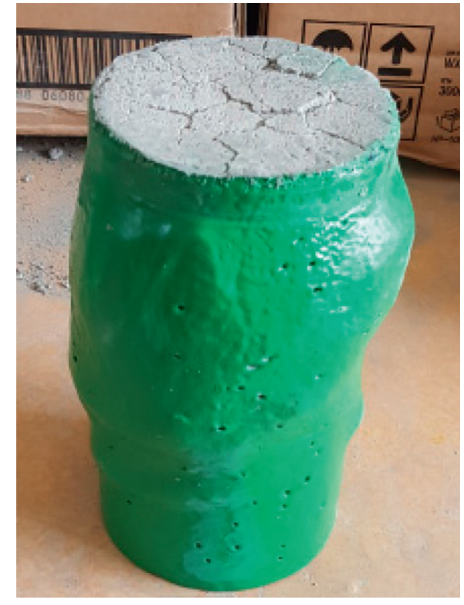

FIgURE 3: Failure mode of polyurea-reinforced concrete cylinder.

ductility. The cause of the insufficient ductility of the S51 specimen is due to the uneven distribution of steel fibers owing to their nonuniform scattering prior to the spraying. After the occurrence of a concrete crack, the beam carries the additional load and reaches the second peak load. As indicated in Table 3, the second peak loads of the FRPUreinforced specimens are higher than those of the polyureareinforced specimen, which is the reinforcement effect from the fibers.

Figure 5 shows the failure modes of the specimens. Upon initial loading, the flexure-resisting capacity is retained by the concrete, as well as the polyurea or FRPU. Upon the occurrence of the concrete cracks, the load abruptly deteriorates. Without a polyurea or FRPU reinforcement, the concrete beams abruptly fail under a load. The flexural capacity after the concrete cracks occurs is retained to a certain degree or even increased owing to the tensile strength of the polyurea or FRPU. The polyurea- or FRPU-reinforced concrete beams display a gradual increase in flexural ductility and deflection prior to ultimate failure. It was shown that the strengthened concrete beams ultimately fail through a fracture of the polyurea or FRPU.

Figure 6 shows the load-deflection curves of the specimens depending on the fiber types for a spray thickness of $3 \mathrm{~mm}$. The plots are divided into three groups: (a) group 1 is CNTs strengthened by $2 \%$, or milled glass or steel fibers strengthened by $5 \%$, (b) group 2 is CNTs strengthened by $4 \%$, or milled glass or steel fibers strengthened by $7 \%$, and (c) group 3 is CNTs strengthened by $6 \%$, or milled glass or 

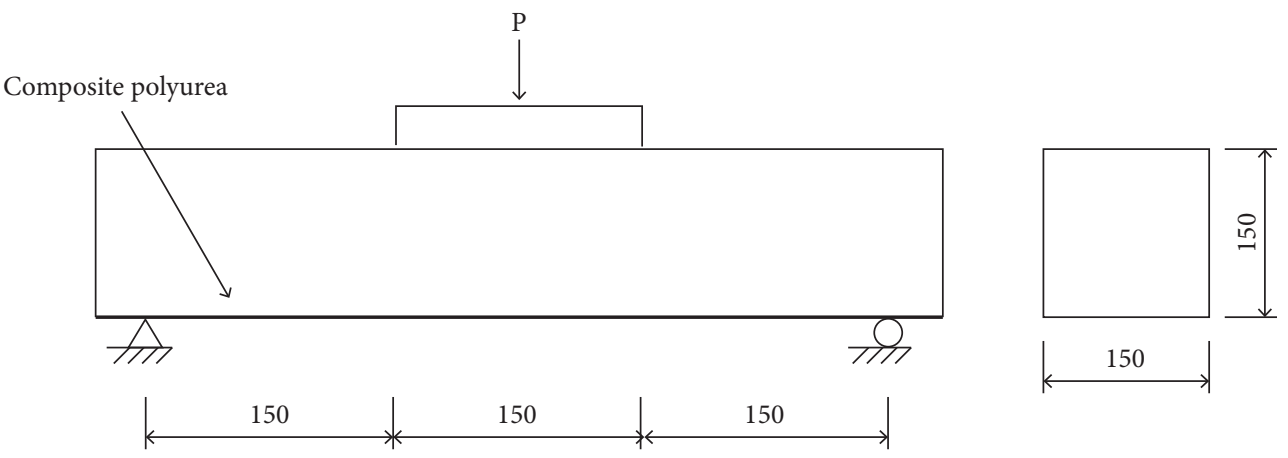

FIGURE 4: Loading system of concrete beam (unit: $\mathrm{mm}$ ).

TABle 3: Summary of experimental results.

\begin{tabular}{|c|c|c|c|c|c|}
\hline \multirow{2}{*}{ Specimen } & \multicolumn{2}{|c|}{ Load-carrying capacity } & \multirow{2}{*}{ Second peak load $(\mathrm{kN})$} & \multicolumn{2}{|c|}{ Flexural ductility } \\
\hline & Peak $(\mathrm{kN})$ & Ratio & & Ductility $(\mathrm{kN} \cdot \mathrm{mm})$ & Ratio \\
\hline $\mathrm{C} 21$ & 24.41 & 1.20 & 10.35 & 138.36 & 1.98 \\
\hline $\mathrm{C} 22$ & 20.34 & 1.0 & 8.78 & 69.7 & 1.0 \\
\hline C41 & 21.49 & 1.06 & 13.43 & 135.6 & 1.95 \\
\hline $\mathrm{C} 42$ & 23.96 & 1.18 & 23.72 & 227.45 & 3.26 \\
\hline C61 & 23.1 & 1.14 & 15.85 & 160.1 & 2.30 \\
\hline C62 & 18.98 & 0.93 & 12.97 & 102.09 & 1.46 \\
\hline F51 & 22.25 & 1.09 & 11.61 & 97.74 & 1.40 \\
\hline F52 & 22.79 & 1.12 & 17.3 & 190.85 & 2.74 \\
\hline F71 & 23.99 & 1.18 & 22.6 & 231.77 & 3.32 \\
\hline F72 & 31.19 & 1.53 & 31.2 & 355.9 & 5.10 \\
\hline F101 & 23.2 & 1.14 & 20.38 & 188.33 & 2.70 \\
\hline F102 & 22.55 & 1.11 & 18.65 & 147.17 & 2.11 \\
\hline S51 & 21.45 & 1.05 & 13.6 & 58.56 & 0.84 \\
\hline S52 & 24.63 & 1.21 & 20.8 & 120.1 & 1.72 \\
\hline S71 & 22.12 & 1.09 & 17.38 & 116.57 & 1.67 \\
\hline S72 & 27.01 & 1.33 & 27.02 & 254.5 & 3.65 \\
\hline S101 & 21.43 & 1.05 & 15 & 85.4 & 1.22 \\
\hline S102 & 30.5 & 1.50 & 30.5 & 228.53 & 3.28 \\
\hline PO1 & 20.34 & 1.0 & 8.75 & 69.7 & 1.0 \\
\hline Plain & 20.86 & & & 2.27 & \\
\hline
\end{tabular}

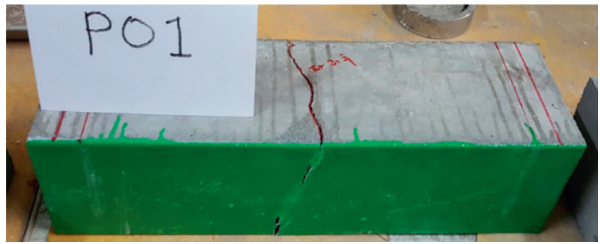

(a)

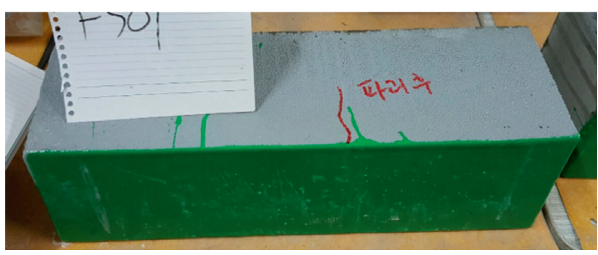

(c)

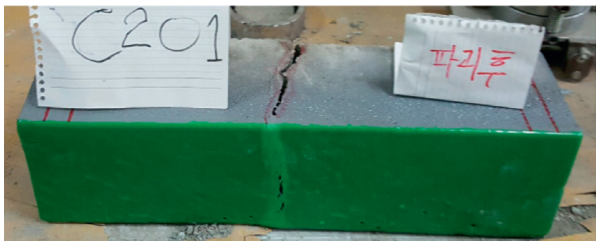

(b)

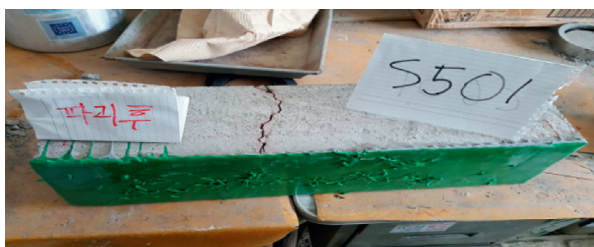

(d)

Figure 5: Failure mode of specimens: (a) PO1; (b) C21; (c) F51; (d) S51.

steel fibers strengthened by $10 \%$. We assume that the beams ultimately fail when the load abruptly decreases after retaining sufficient ductility since the crack occurrence. It was found that the polyurea- or FRPU-reinforced specimens retain sufficient flexural ductility owing to their expansibility. The specimens of group 1 in Figure 6(a) exhibit a 


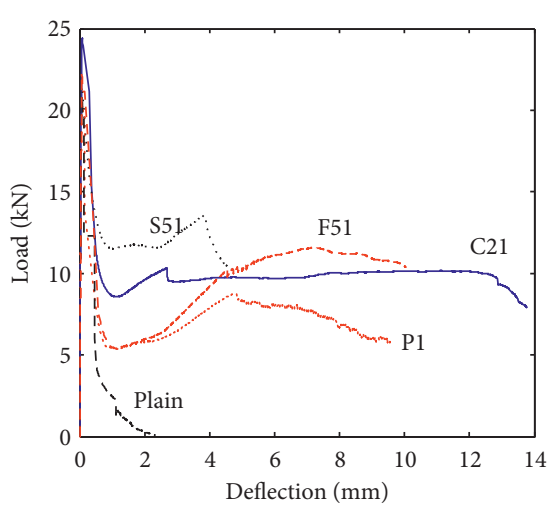

(a)

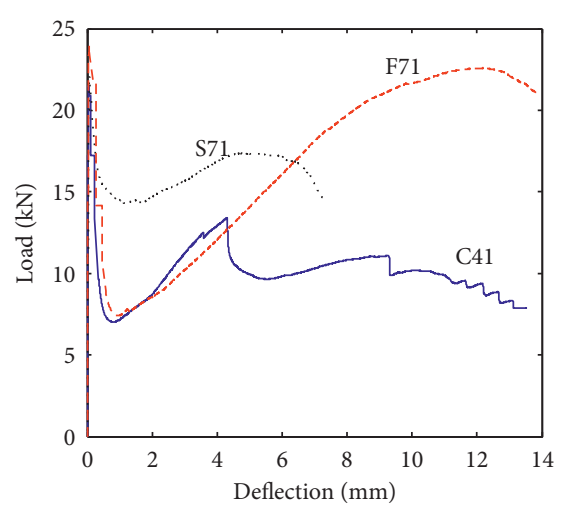

(b)

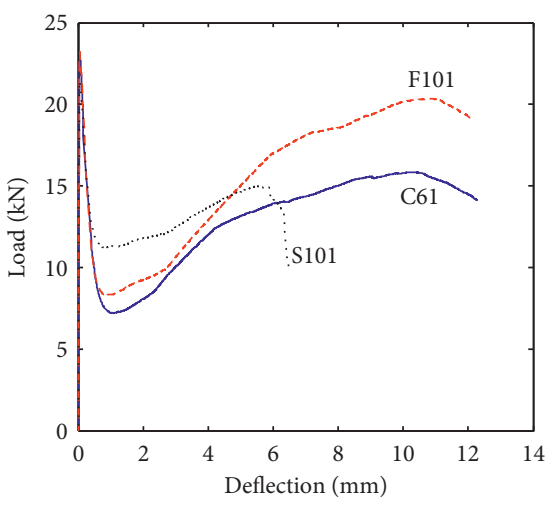

(c)

FIGURE 6: Load-deflection curves (spraying thickness of $3 \mathrm{~mm}$ ): (a) group one; (b) group two; (c) group three.

similar load-deflection relationship prior to a concrete crack. Specimen C21 reinforced by CNTs also exhibits sufficient ductility. The specimens P1, F51, and S51 resist a load with a constant magnitude after a crack occurrence. The steel fibers of $5 \mathrm{~mm}$ in length are manually scattered on the beam surface prior to the polyurea spraying, and their even distribution cannot be expected. Thus, specimen S51 abruptly fails and exhibits little ductile behavior. It was found that the specimens reinforced by milled glass fibers or CNTs retain more load-carrying capacity and flexural ductility than those using polyurea only. The specimens of group 2 in Figure 6(b), which contain more fibers than those in group 1 in Figure 6(a), show a higher second peak load and more flexural ductility. Specimen C41 exhibits an abrupt load deterioration after the second peak load although the ductility is retained to a certain degree. The load deterioration in specimen C41 is caused by the uneven thickness of the FRPU and the uneven distribution of the CNT. It is difficult to obtain a precise and constant thickness because the spraying operation is manually conducted by experts. In addition, it is not easy to evenly disperse the fibers on the concrete surface. It has been shown that specimen F71 retains a high strength after concrete cracks occur, and thus the second peak load nearly reaches the peak load with an increase in the deflection. In group 3 in Figure 6(c), the specimen reinforced by steel fibers abruptly fails at a lower load than that in group 2. It has been estimated that an abrupt failure and low ductility are due to more irregular scattering with an increase in the weight-to-content ratio. It has been observed that the reinforcement by steel fibers has a limitation in the spraying operation regardless of the weightto-content ratio. The specimen reinforced by CNTs in group 3, shown in Figure 6(c), exhibits a higher load-carrying capacity and more ductility after the cracking than that in group 2. The CNTs have a higher cost than the other fibers. In addition, the F101 specimen strengthened by milled glass fibers retains more load-carrying capacity and flexural ductility with an increase in the weight-to-content ratio.

Figure 7 shows the load-deflection curves of the specimens reinforced by FRPU of $5 \mathrm{~mm}$ in thickness. The load abruptly reduces upon the occurrence of the first flexural concrete cracking. After this stage, the load is resisted by the FRPU at the flexural tension face and gradually increases with the deflection. Compared with specimens of $3 \mathrm{~mm}$ in thickness, the increase in spraying thickness leads to an enhancement in the load-carrying capacity as well as the flexural ductility. This is due to the increase in the tensionresisting area and the corresponding force. The plots also indicate that the toughness and dissipated energy increase with an increase in the weight-to-content ratio. The specimens reinforced by steel fibers exhibit an enhanced peak load-carrying capacity with an increase in the weight-tocontent ratio and the highest flexural ductility at the weightto-content ratio of $7 \%$. However, it is difficult to state that the most effective ratio is $7 \%$ because of the uneven coating thickness of the FRPU and the nonuniform distribution of the steel fibers. The concrete beams reinforced by $2 \%$ or $6 \%$ CNTs rarely display more load-carrying capacity and flexural ductility than at a weight-to-content ratio of $4 \%$. Based on the synthetic prediction shown in Figure 7, we can predict that the optimum weight-to-content ratio is approximately $4 \%$. The specimens containing milled glass fibers depending on the weight-to-content ratio exhibit an extremely similar tendency as those using CNTs. The optimum weight-tocontent ratio of glass fibers should be approximately $7 \%$ in terms of economy and strength.

Figure 8 compares the strengthening effect depending on the weight-to-content ratio of the reinforcement fibers and coating thickness. It can be expected that the load-carrying capacity and flexural ductility should be enhanced with an increase in the coating thickness or weight-to-content ratio because of the increased flexure-resisting strength. However, the $\mathrm{C} 2, \mathrm{C} 6$, and F10 series specimens represent the deteriorated load-carrying capacity and flexural ductility despite the increased coating thickness. It can be estimated that the results are derived from the uneven thickness of the FRPU, as well as the discontinuous and nonuniform distribution of the fibers. The specimens reinforced by steel fibers exhibit an enhanced load-carrying capacity and flexural ductility. However, the specimens of the S10 series represent less flexural ductility than of the S7 series because of the nonuniform distribution through an excessive steel fiber content. It has been 


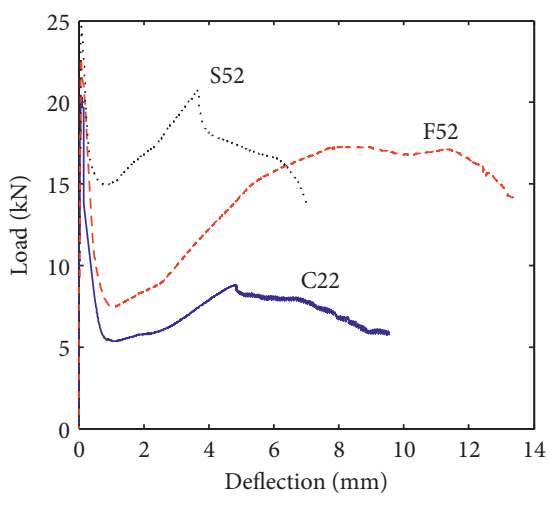

(a)

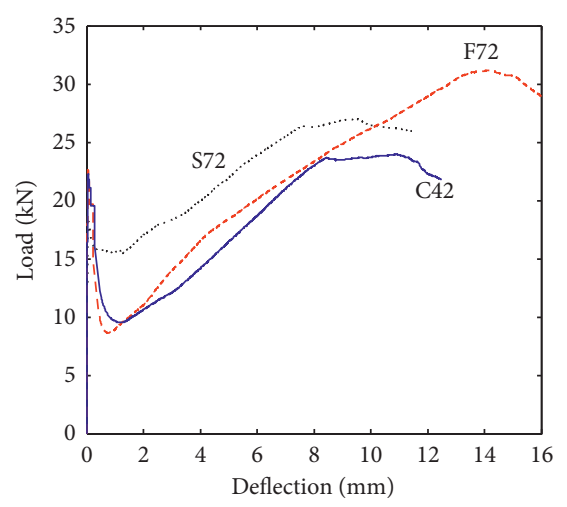

(b)

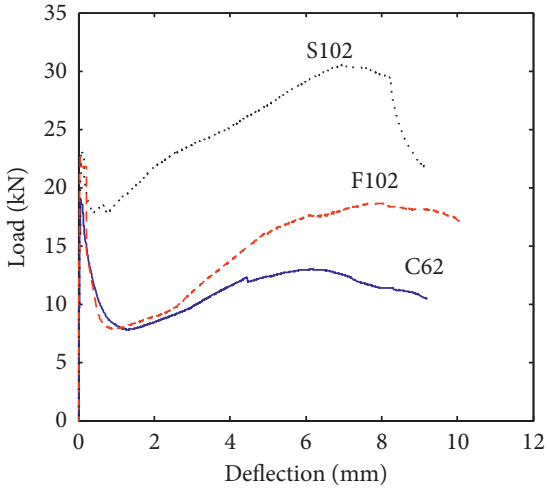

(c)

FIGURE 7: Load-deflection curves (spraying thickness of $5 \mathrm{~mm}$ ): (a) group one; (b) group two; (c) group three.

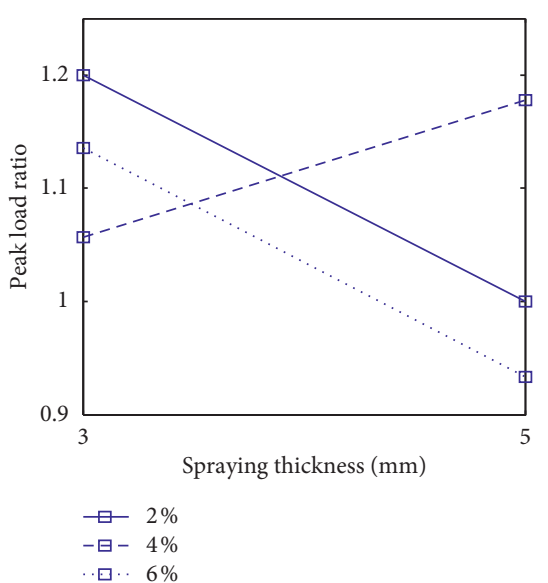

(a)

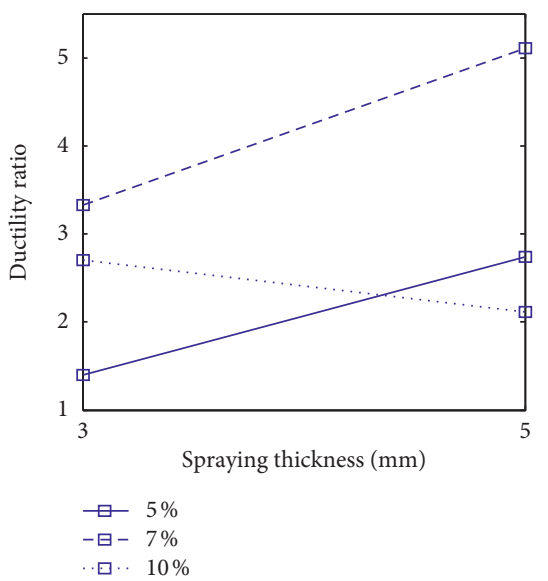

(d)

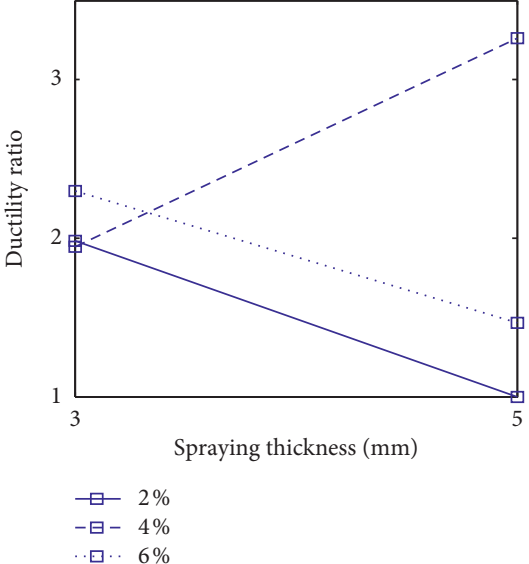

(b)

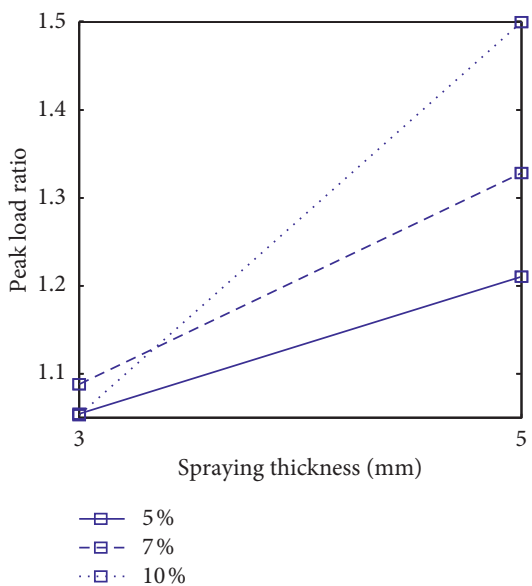

(e)

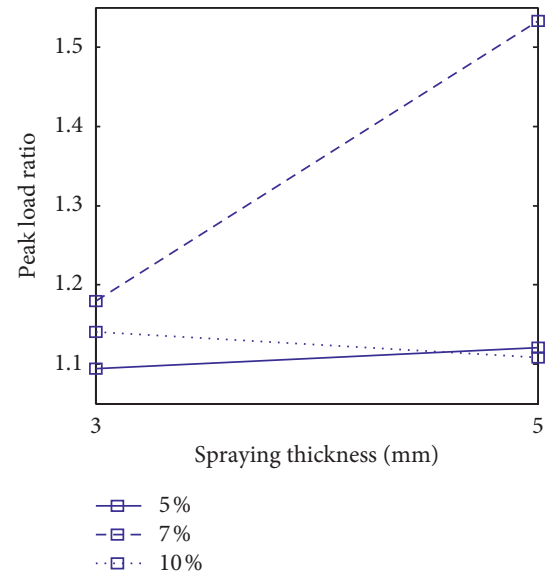

(c)

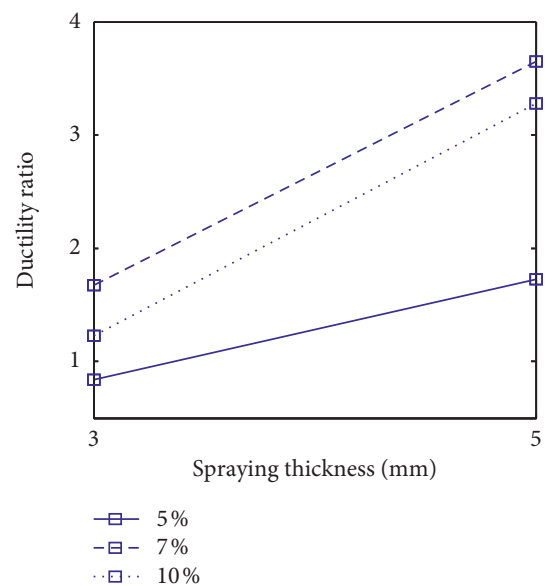

(f)

FIGURE 8: Peak load ratio and ductility ratio according to spraying thickness: (a) C series-load ratio; (b) C series-ductility ratio; (c) F seriesload ratio; (d) F series-ductility ratio; (e) S series-load ratio; (f) S series-ductility ratio.

demonstrated that the specimens of the C4, F5, and F7 series retain a stable load-carrying capacity and flexural ductility upon the variation of the coating thickness and weight-tocontent ratio of the fibers in comparison with the other specimens. It can be concluded from the experiments that the
FRPU method reinforced by $5 \%$ or $7 \%$ milled glass fibers is the most effective in terms of the economy, strengthening, and construction of all reinforcements.

This observation can be seen in Figure 9, which shows that the $4 \%$ CNT specimens have an enhanced load-carrying 


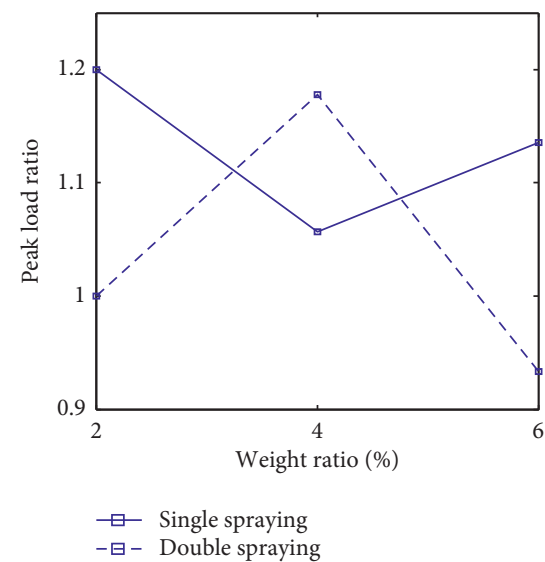

(a)

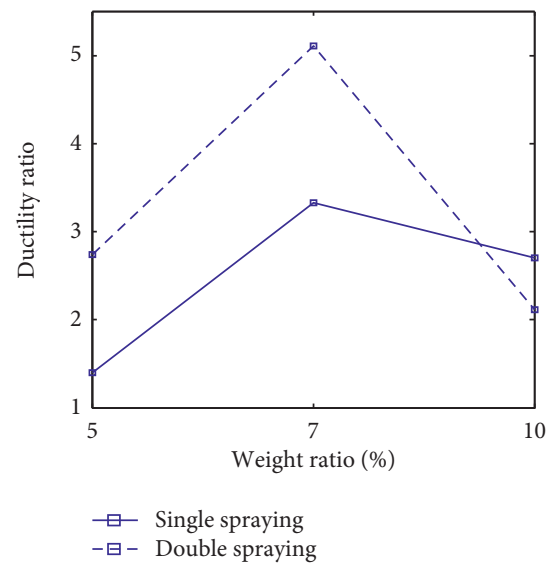

(d)

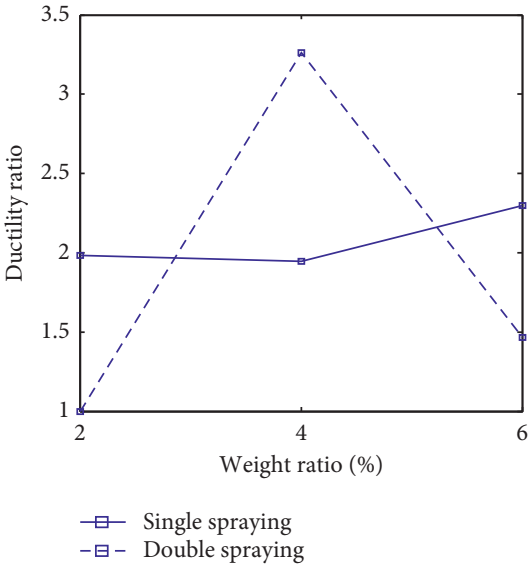

(b)

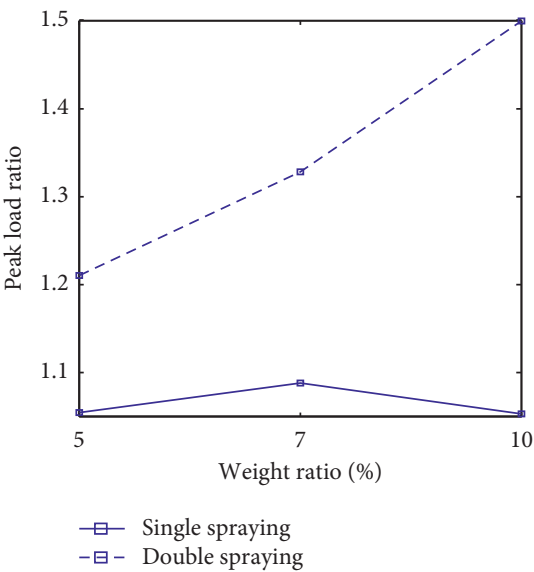

(e)

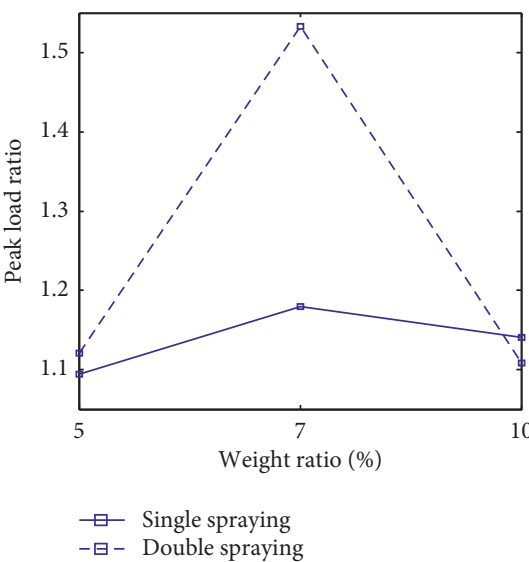

(c)

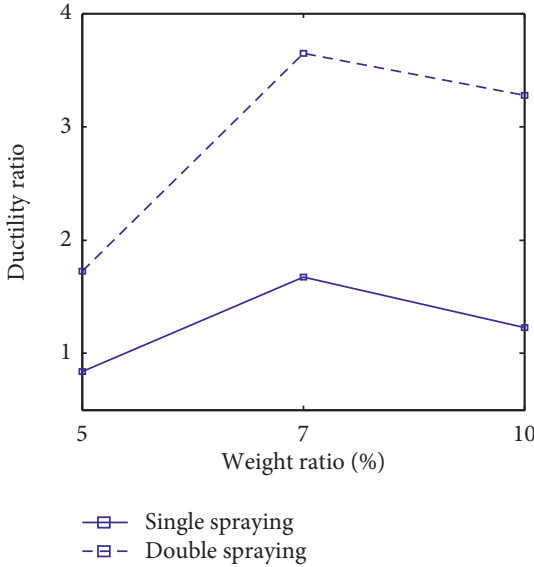

(f)

FIgURE 9: Peak load ratio and ductility ratio according to weight ratio: (a) CNT-load ratio; (b) CNT-ductility ratio; (c) glass fiber-load ratio; (d) glass fiber-ductility ratio; (e) steel fiber-load ratio; (f) steel fiber-ductility ratio.

capacity and flexural ductility. In addition, the specimens of $5 \%$ or $7 \%$ milled glass fibers exhibit stable results in enhancing the load-carrying capacity and flexural ductility. The specimens reinforced by steel fibers show an enhanced load-carrying capacity and flexural ductility with an increase in the coating thickness. However, this strengthening method has difficulty in terms of spraying, and a definite increase in the load-carrying capacity and flexural ductility can rarely be expected owing to the discontinuous flexural loading path through the nonuniform distribution of the steel fibers.

\section{Conclusions}

This study investigates the applicability of the FRPU coating technique in the retrofitting of concrete structures. The FRPU coating approach can avoid a failure by debonding from the concrete surface. The test parameters include the fiber type, such as glass, carbon, and steel fibers, the coating thickness, and the fiber weight-to-content ratio. The reinforcement by steel fibers has a limitation in terms of a spraying operation regardless of the weight-to-content ratio, because fibers should be manually scattered on the member surface prior to spraying. The FRPU approach when applying CNTs has a difficulty in terms of the flexural capacity, because the low-density CNTs make up a high volume of the FRPU, which is a disadvantage owing to the expansiveness. The specimens with $5 \%$ or $7 \%$ milled glass fibers exhibit stable results in enhancing the load-carrying capacity and flexural ductility. This experiment indicates that the FRPU coating approach using milled glass fibers is more effective than the application of CNTs or steel fibers for enhancing the load-carrying capacity and improving the flexural ductility.

\section{Data Availability}

The data used to support the findings of this study are included within the article.

\section{Conflicts of Interest}

The authors declare that there are no conflicts of interest regarding the publication of this paper. 


\section{References}

[1] S. Parniani and H. Toutanji, "Monotonic and fatigue performance of RC beams strengthened with a polyurea coating system," Construction and Building Materials, vol. 101, no. 1, pp. 22-29, 2015.

[2] A. E. Marawan, A. S. Debaiky, and N. N. Khalil, "Shear and flexural behavior of R.C. beams strengthened with polyurea spray," International Journal of Advance Research in Science and Engineering, vol. 4, no. 11, pp. 12-26, 2015.

[3] K. Kamonchaivanich, K. Kuboyama, and T. Ougizawa, "Effect of elastic modulus and position of polyurea coating on flexural strength of coated ceramic tiles by experiments and finite element analysis," Journal of Coatings Technology and Research, vol. 16, pp. 1-11, 2019.

[4] O. Gedik, C. Demir, and A. Ilki, "Effect of unconfined concrete strength on the strength and deformability predictions of FRP confined concrete," in Proceedings of the Second Official International Conference of International Institute for FRP in Construction for Asia-Pacific Region, pp. 265-270, Seoul, Korea, December 2009.

[5] M. Samaan, A. Mirmiran, and M. Shahawy, "Model of concrete confined by fiber composites," Journal of Structural Engineering, vol. 124, no. 9, pp. 1025-1031, 1998.

[6] H. Toutanji, "Stress-strain characteristics of concrete columns externally confined with advanced fiber composite sheets," ACI Materials Journal, vol. 96, no. 3, pp. 397-404, 1999.

[7] Y. Xiao and H. Wu, "Compressive behaviour of concrete confined by carbon fiber composite jackets," Journal of Materials in Civil Engineering, vol. 12, no. 2, pp. 139-146, 2000.

[8] A. Ilki and N. Kumbasar, "Compressive behaviour of carbon fibre composite jacketed concrete with circular and noncircular cross-sections," Journal of Earthquake Engineering, vol. 7, no. 3, pp. 381-406, 2003.

[9] L. Lam and J. G. Teng, "Design-oriented stress-strain model for FRP-confined concrete," Construction and Building Materials, vol. 17, no. 6-7, pp. 471-489, 2003.

[10] G. Manfredi and R. Realfonzo, "Models of concrete confined by fiber composites," in Proceedings of the 5th International Conference on Fibre-Reinforced Plastics for Reinforced Concrete Structures, FRPRCS5, vol. 1, pp. 865-873, London, UK, July 2001.

[11] D. S. A. Gideon and P. Alagusundaramoorthy, "Flexural retrofit of RC beams using CFRP laminates," IOP Conference Series: Materials Science and Engineering, vol. 431, no. 7, Article ID 072006, 2018.

[12] A. Li, C. Diagana, and Y. Delmas, "Shear strengthening effect by bonded composite fabrics on RC beams," Composites Part B: Engineering, vol. 33, no. 3, pp. 225-239, 2002.

[13] M. B. S. Alferjani, A. A. B. A. Samad, B. S. Elrawaff, N. B. Mohamad, and M. H. B. Ahmad, "Shear strengthening of reinforced concrete beams using carbon fiber reinforced polymer laminate: a review," American Journal of Civil Engineering, vol. 2, no. 1, pp. 1-7, 2014.

[14] T. B. Carlos, J. P. C. Rodrigues, R. C. A. De Lima, and D. Dhima, "Experimental analysis on flexural behaviour of RC beams strengthened with CFRP laminates and under fire conditions," Composite Structures, vol. 189, no. 1, pp. 516-528, 2018.

[15] S. F. Brena, R. M. Bramblett, S. L. Wood, and M. E. Kreger, "Increasing flexural capacity of reinforced concrete beams using carbon fiber-reinforced polymer composites," ACI Structural Journal, vol. 100, no. 1, pp. 36-46, 2003.
[16] S. F. Brena and B. M. Macri, "Effect of carbon-fiber-reinforced polymer laminate configuration on the behavior of strengthened reinforced concrete beams," Journal of Composites for Construction, vol. 8, no. 3, pp. 229-240, 2004.

[17] P. J. Fanning and O. Kelly, "Ultimate response of RC beams strengthened with CFRP plates," Journal of Composites for Construction, vol. 5, no. 2, pp. 122-127, 2001.

[18] P. Alagusundaramoothy, I. E. Harik, and C. C. Choo, "Flexural behavior of $\mathrm{R} / \mathrm{C}$ beams strengthened with carbon fiber reinforced polymer sheets or fabric," Journal of Composites for Construction, vol. 7, no. 4, pp. 292-301, 2003.

[19] F. Ceroni, "Experimental performances of RC beams strengthened with FRP materials," Construction and Building Materials, vol. 24, no. 9, pp. 1547-1559, 2010.

[20] H. V. S. Gangarao and P. V. Vijay, "Bending Behavior of Concrete Beams Wrapped with Carbon Fabric," Journal of Structural Engineering, vol. 124, no. 1, pp. 3-10, 1998.

[21] G. Spadea, F. Bencardino, and R. N. Swamy, "Structural behavior of composite RC beams with externally bonded CFRP," Journal of Composites for Construction, vol. 2, no. 3, pp. 132-137, 1998.

[22] T. Uomoto, H. Mutsuyoshi, F. Katsuki, and S. Misra, "Use of fiber reinforced polymer composites as reinforcing material for concrete," Journal of Materials in Civil Engineering, vol. 14, no. 3, pp. 191-209, 2002.

[23] H. K. Mahiyar and M. Soni, “An experimental study of flexural strength of concrete beam reinforced with fiber reinforced polymer," International Research Journal of Engineering and Technology, vol. 4, no. 11, pp. 1933-1939, 2017.

[24] C. E. Greene and J. J. Myers, "Flexural and shear behavior of reinforced concrete members strengthened with a discrete fiber-reinforced polyurea system," Journal of Composites for Construction, vol. 17, no. 1, pp. 108-116, 2013.

[25] N. L. Carey and J. J. Myers, "Discrete fiber reinforced polymer systems for repair of concrete structures: polyurea-fiber characterization results," American Concrete Institute, vol. 275, no. 16, pp. 1-14, 2011. 